\title{
ESTUDIOS
}

\section{El don y lo imposible. Figuras de lo cuasi-trascendental en Jacques Derrida}

\author{
Gift and impossibility. \\ Representations of the quasi-transcendental in \\ Jacques Derrida
}

DIEGO ABADI

Universidad de Buenos Aires (Argentina)

\section{RESUMEN}

En el presente artículo intentaremos hacer una lectura local que a su vez pueda quizá aportar herramientas para una lectura transversal de la obra derrideana. Por una parte, llevaremos adelante un comentario de Dar (el) tiempo, extrayendo de allí las nociones de «don» e «imposibilidad» a la vez que resaltando su implicación recíproca. Por otra, intentaremos mostrar cómo a través de estas nociones, y mediante su comprensión según la lógica de lo cuasi-trascendental, pueden hallarse elementos útiles para una lectura de conjunto de la producción derrideana.

PALABRAS CLAVE

DERRIDA, DON, IMPOSIBILIDAD, CUASI-TRASCENDENTAL

\section{ABSTRACT}

In this article we will try to do a local reading which may also contribute tools for a general reading of Derrida's work. On the one hand, we will do a brief commentary on Given Time,

(C) Contrastes. Revista Internacional de Filosofía, vol. XVIII (2013), pp. 9-27. ISSN: 1136-4076

Licenciatura de Filosofía, Universidad de Málaga, Facultad de Filosofía y Letras Campus de Teatinos, E-29071 Málaga (España) 
focusing in the notions of «gift» and «impossibility» and in their mutual implication. On the other hand, we will try to show how, through these notions, and their comprehension following the logic of the quasi-transcendental, one can find useful elements for a general reading of Derrida's production.

\author{
KEYWORDS \\ DERRIDA, GIFT, IMPOSSIBILITY, QUASI-TRANSCENDENTAL
}

PARA LLEVAR ADELANTE UNA LECTURA que, si bien local y por tanto emplazada específicamente en un comentario de Dar (el) tiempo, ${ }^{1}$ pueda a su vez aportar herramientas que permitan sumar inteligibilidad a la obra derrideana en su conjunto, dividiremos la exposición del presente artículo en tres momentos: partiremos de una noción aparentemente empírica (el don), la conduciremos hasta el límite en que tal empiricidad deviene imposible y una comprensión trascendental parece imponerse, para finalmente construir con ella una noción cuasi-trascendental en la que la dicotomía empírico/trascendental pierde toda pertinencia. Dicho método de exposición nos permitirá acercarnos a una visión de conjunto, en la medida en que duplica y explicita una estrategia de lectura específicamente deconstructiva. Esta consiste, según nuestra perspectiva, en un recurrente esfuerzo por mostrar la incapacidad del par de categorías «empírico» y «trascendental» para dar cuenta de la aparición de el o lo Otro en tanto singularidad.

Reconstruyendo muy sucintamente tal crítica, podría decirse que lo que dicho par asegura es una clausura por la cual cada uno de los términos reenvía necesariamente a $s u$ otro. Es decir, al detenerse en lo trascendental, todo lo que no sea propiamente trascendental será necesariamente empírico, mientras que a la inversa, al detenerse en lo empírico, todo lo que no sea propiamente empírico será necesariamente trascendental. Tal esquema reafirma así la lógica característica del logocentrismo mediante la cual la filosofía se apropia de lo otro (lo empírico, lo accidental, lo singular) comprendiéndolo como su otro (lo no- o lo anti-filosófico). Con los cuasi-conceptos que pone en juego en cambio la lógica cuasi-trascendental esto no sucede. En aquellos pares no puede decirse, al detenerse en uno de los términos, que lo que quede por fuera de éste sea $s u$ otro definido, ya que cada uno de ellos está cruzado por una alteridad absoluta

1 J Derrida, Dar (el) tiempo. 1. La moneda falsa, tr. Cristina de Peretti. Barcelona: Paidós, 1995. 
que impide identificarlo como un término delimitado. Es decir, al no poseer un campo propio, lo que no puede hacerse es precisamente detenerse en un término. Así, al no poder remitir la alteridad a un afuera definido, esta agujerea el campo de lo propio desde su origen. La operación de lectura que despliega Derrida puede comprenderse entonces como un mostrar la empiricidad irreductible que subyace en lo trascendental, señalando en el mismo gesto la trascendentalidad inevitable que subyace en lo empírico. Operación que termina borrando pues los límites entre empírico y trascendental y conduciendo a la lógica aporética o de double bind como la de los pares posible/imposible, condicionado/incondicionado o derecho/justicia.

\section{LA LÓGICA GENERAL DEL DON}

Dar (el) tiempo puede considerarse, entre otras cosas, como una respuesta, un replanteo o una reescritura del Ensayo sobre el don de Marcel Mauss; es decir, parte de elementos que este último utiliza, para transcribirlos a un vocabulario deconstructivo. Detengámonos en primer lugar en una especie de descripción empírica del don que realiza Derrida y que servirá como base para desarrollar tanto una crítica a Mauss como una lógica alternativa del don.

Para que una acción se conciba como un don, se dice, tienen que cumplirse ciertas condiciones mínimas. En primer lugar, tiene que haber una intención de dar. No se diría que lo que sucede es una donación, si aquel que la lleva a cabo no posee la intención o el deseo de hacerla efectiva. A tal intención deben sumárseles, por un lado, la determinación de aquello que se quiere dar, y la de aquel a quien está dirigida la acción. Así, habría un esquema ternario presupuesto para cualquier donación: alguien (A), da algo (B), a alguien (C). Sin la posibilidad de identificar, en sí mismos y en su diferencia relativa, esos tres elementos, no podría considerarse a una acción como una donación. Ahora bien, ello no implica que quien da o quien recibe sean personas individuales; de hecho, lo más habitual en los casos empíricos actuales de donación es que o el agente o el paciente de la donación sean instituciones o sujetos colectivos. Como así tampoco aquel «algo» que habíamos nombrado como elemento (B) tiene que ser una cosa o un objeto en el sentido habitual, puede tratarse de un objeto simbólico. Puede, por ejemplo, darse reconocimiento, apoyo, gratitud, etc.

Ahora, si bien tal esquema ternario es una condición necesaria, es preciso todavía que a éste se le agregue otra característica: para que haya don, no tiene que haber ni reciprocidad ni devolución, ni deuda ni contra-don, ya que si así fuera, estaríamos ante un caso de intercambio. Tal cosa resulta evidente si, por ejemplo, el donatario devuelve al donador la cosa dada inmediatamente, aunque tampoco deja de cancelarse el don si la restitución se difiere en el tiempo. Pero si bien a primera instancia esta condición no parece problemática, es a través de ella que Derrida conducirá el don a su límite empírico. Para que haya don, 
entonces, este no tiene que ser siquiera reconocido. Ni por el donatario ni por el donador. Tal afirmación extrema se sostiene en el hecho marcado de que aquello que se da no necesariamente debe ser una cosa material. En lo que respecta al donatario, el mero reconocimiento del don como tal es suficiente para anular el don.

¿Por qué? porque éste devuelve, en (el) lugar -digamos- de la cosa misma, un equivalente simbólico. Lo simbólico, aquí, ni siquiera puede decirse que reconstruya el intercambio ni que anule el don con la deuda. No re-construye un intercambio que, al no tener ya lugar como intercambio de cosas o de bienes, se transfiguraría en intercambio simbólico. Lo simbólico abre y constituye el orden del intercambio y de la deuda, la ley o el orden de la circulación en donde se anula el don. Basta, pues, con que el otro perciba el don, que lo perciba no sólo en el sentido en que, como suele decirse en francés o en castellano, se percibe un bien, un dinero o una recompensa, sino que perciba la naturaleza de don, que perciba el sentido o la intención, el sentido intencional del don, para que este simple reconocimiento del don como don, como tal, incluso antes de convertirse en reconocimiento como gratitud, anule el don como don. La mera identificación del don parece destruirlo. ${ }^{2}$

Lo mismo sucede en lo que respecta al donador que, si da, «no debe verlo ni saberlo tampoco, pues de no ser así, empieza, de entrada, en cuanto tiene intención de dar, a dar por descontado un reconocimiento simbólico, a felicitarse, a aprobarse a sí mismo, a gratificarse, a congratularse, a restituirse simbólicamente el valor de lo que acaba de dar, de lo que cree haber dado, de lo que se prepara a dar». ${ }^{3}$ Así, se llega a una formulación aporética: si la identificación de los tres elementos mencionados -el donador, lo donado y el donatario- es condición del reconocimiento de un acontecimiento de don, aquella misma identificación como don -con la consiguiente identificación de sus elementos- lo anula en cuanto tal, por el hecho de inscribirlo en un esquema de restitución. Derrida concluye por tanto: «En último extremo, el don como don debería no aparecer como don: ni para el donatario, ni para el donador. No puede ser ni haber don como don más que si no es/está presente como don». ${ }^{4}$

Habiendo entonces ya delineado los márgenes conceptuales sobre los que se montará el análisis derrideano, puede proseguirse hacia la lectura de Mauss. El Ensayo sobre el don elevará a una potencia mayor la tensión señalada, en la medida en que brinda elementos de gran utilidad, no solo para plantear la cuestión de cómo identificar un acontecimiento de don, sino a su vez la cuestión

2 Ibid.,pp. 22-23.

3 Ibid., p. 23.

4 Ibid. 
derivada de cómo identificar un sistema del don. Así, atravesando el Ensayo con esa problemática en vista, no tardarán en surgir los interrogantes, muy relevantes para todo el pensamiento deconstructivo, sobre la posibilidad de la sistematicidad en general. Derrida encuentra en el texto de Mauss un punto de partida claro: «se trata de pensar la racionalidad económica del crédito a partir del don y no al revés. El don sería originario; sería el verdadero productor del valor puesto que es el valor de los valores en sí mismo». ${ }^{5}$ Tal sistema del don, que comprenderá tanto a la circulación de los bienes económicos como al potlatch, será apodado «sistema de los dones intercambiados». La combinación de los nombres de ese sintagma es doblemente problemática para Derrida. Según lo ya visto, los regímenes del don y del intercambio serían excluyentes, mientras que por otra parte, también sería problemática la conjunción de un sistema de los dones. Pero dejando por el momento estas cuestiones en suspenso, volvamos a la letra del Ensayo. Para Mauss, tal como lo indica el sintagma «dones intercambiados», si bien no hay una incompatibilidad entre el don y el intercambio, sí hay una diferencia que permite su conjunción. Así, entre el don, cuya lógica tendría valor estructural, y el intercambio como circulación de bienes, la diferencia vendría dada por el carácter de lo excesivo, que sería el rasgo esencial del don. También el potlatch, en tanto derivado del don, vendría a estar definido por tal carácter, transformándose en una especie de exceso del exceso, un exceso del don. En lo que respecta a lo primero, el exceso del don por sobre el mero intercambio se determina, según Mauss, en la forma de un plazo temporal. Mientras que en un proceso de intercambio comercial una transacción implica en teoría una inmediatez que hace indistinguible lo dado y lo tomado, el intercambio de dones obliga a tomarse un tiempo. Mauss dice:

Los dones circulan -como hemos visto- en Melanesia, en Polinesia, con la certeza de que serán devueltos, «seguridad» que reside en la virtud de la cosa dada que, a su vez, es dicha «seguridad». Pero, en toda sociedad posible, forma parte de la naturaleza del don el obligar dentro de un plazo. Por definición, ni siquiera una comida en común, una distribución de kawa, un talismán que uno se lleva, pueden ser devueltos de inmediato. Es necesario un «tiempo» para llevar a cabo cualquier contraprestación. ${ }^{6}$

El potlach, por su parte, en tanto exceso del don -es decir, exceso del exceso- se ubica en el límite de la destrucción misma del don. Así lo explica Mauss:

5 Ibid., p. 50.

6 Ibid., p. 45. 
En ningún otro lugar están el prestigio del jefe y el prestigio de su clan tan ligados al gasto y a la exactitud a la hora de devolver con usura los dones aceptados, de modo que los que crean la obligación se tornen a su vez obligados. El consumo y la destrucción no conocen allí realmente barrera alguna. En algunos potlatch hay que gastar todo lo que se tiene y no (res)guardar nada. (...) El matrimonio de los hijos, la posición en las cofradías no se obtienen sino mediante potlatch intercambiados y devueltos. Y también se pierden en el potlatch, igual que se pierden en la guerra, en el juego, en las carreras, en el combate. En un buen número de casos, no se trata siquiera de dar ni de devolver, sino de destruir, a fin de no querer siquiera que parezca que se desean que se les devuelva nada. ${ }^{7}$

\section{ECONOMÍA Y ANECONOMÍA}

Es preciso introducir, para continuar hacia la contaminación de este esquema entre el don, el intercambio y el potlach, dos categorías propiamente derrideanas que de alguna manera sintetizan todos los planteos hasta aquí expuestos. El concepto de economía, desde su primera aparición en textos tempranos, tuvo un alcance mayor al que se le asocia a dicha disciplina en tanto disciplina regional. Para Derrida, la raíz del oikos en el término economía (oikonomia), más que designar un campo específico y regional de la ley (nomos), designaría a la ley sin más. En una suerte de tautología, la ley de lo propio vendría a ser lo propio de la ley. Así, Derrida explica:

¿Qué es la economía? Entre sus predicados o sus valores semánticos irreductibles, sin duda, la economía comporta los valores de ley (nomos) y de casa (oikos es la casa, la propiedad, la familia, el hogar, el fuego de dentro). Nomos no significa sólo la ley en general sino también la ley de distribución (nemein), la ley de la partición, la ley como partición (moira), la parte dada o asignada, la participación. Otro tipo de tautología implica ya a lo económico en lo nómico como tal. En cuanto hay ley, hay partición: en cuanto hay nomia, hay economía. ${ }^{8}$

Este concepto de economía anuda entonces el campo de lo «material» (cosas u objetos en su sentido corriente) con el de lo simbólico, a través de la característica de la circulación, poniendo en acto cierta indecidibilidad entre los planos de las condiciones y lo condicionado que abordaremos más adelante. Para el idealismo, por ejemplo, la economía en sentido amplio - en tanto campo de lo material- no sería más que un contenido condicionado por lo que en el extracto anterior se nombraba como simbólico pero que agrupa a la idealidad en general. El materialismo, por su parte, en la medida en que se propone distin-

7 Ibid.,pp. 52-53.

8 Ibid, p. 16. 
guir una estructura trascendental -la economía-, de una superestructura que no sería más que una condición de aquella, no haría más que invertir tal esquema idealista, manteniendo así la lógica que lo estructura..$^{9}$ Tal lógica común entre el idealismo y ciertos materialismos viene dada por otra de las características que Derrida considera definitorias de su concepto de economía; nos referimos a la figura de lo circular que domina toda circulación:

Además de los valores de ley y de casa, de distribución y de partición, la economía implica la idea de intercambio, de circulación, de retorno. La figura del círculo está evidentemente en el centro, si es que todavía se puede decir eso de un círculo. Se encuentra en el centro de toda la problemática de la oikonomia, así como en el de todo el campo económico: intercambio circular, circulación de los bienes, de los productos, de los signos monetarios o de las mercancías, amortización de los gastos, ganancias, sustitución de los valores de uso y de los valores de cambio. Este motivo de la circulación puede dar a pensar que la ley de la economía es el retorno - circular- al punto de partida, al origen, también a la casa. ${ }^{10}$

Así pues, en la medida en que el don implica la neutralización de todo intercambio o proceso de circulación, éste será aneconómico, interrumpiendo la economía. «No porque resulte ajeno al círculo - aclara Derrida-, sino porque debe guardar con el círculo una relación de extrañeza, una relación sin relación de familiar extrañeza. Puede ser que sea en este sentido en el que el don es lo imposible». ${ }^{11}$ Nos encontramos así con una serie de términos que toman el relevo uno del otro: don, aneconomía, imposible. Intentaremos pues a continuación, a través de éste último, no sólo esclarecer los términos recién mencionados, sino a su vez esbozar una hipótesis que pueda quizá servir como clave de lectura del texto derrideano en su conjunto. ${ }^{12}$

9 Es por ello que en Posiciones Derrida aclara: «el significante "materia" solo me parecía problemático en el momento en que su reinscripción no evitaría crear un nuevo principio fundamental, donde, por una regresión teórica, se le reconstituiría en "significado trascendental". El significado trascendental no sólo es el recurso del idealismo en sentido estricto. Siempre puede venir a asegurar un materialismo metafísico. Entonces se convierte en un referente último, según la lógica clásica que implica este valor de referente, o una "realidad objetiva" absolutamente "anterior" a cualquier trabajo de la marca». (J. Derrida, Posiciones, tr. M. Arranz, Valencia: Pre-textos, 1977, p. 85. Traducción modificada.)

10 J. Derrida, Dar (el) tiempo. 1. La moneda falsa, op. cit., p. 16.

11 Ibid., p. 17.

12 Podrían plantearse dos líneas de lectura alrededor de la noción de imposibilidad dentro de los comentadores de Derrida: por un lado, aquella que se ubicaría bajo la firma de John D. Caputo y que interpreta el mesianismo derrideano en clave religiosa, planteando un giro teológico en la obra derrideana ( $c f$. John D. Caputo, The prayers and tears of Jacques Derrida. Religion without religión. Bloomington: Indiana University Press, 1997, pp. 160-230.); por otro, aquella 


\section{CuAsi-TRASCENDENTALES 1: \\ CONDICIONES DE (IM)POSIBILIDAD DE LA EXPERIENCIA}

En Dar (el) tiempo, como en tantos otros lugares, Derrida expresa en su mayor claridad ese vínculo aporético, ese double bind que asedia y constituye a su noción de imposibilidad: «Y esto es así porque lo imposible que aquí parece que se da a pensar es que las condiciones de posibilidad del don [...] designan simultáneamente las condiciones de la imposibilidad del don. Y de antemano podríamos traducir de otro modo: estas condiciones de posibilidad definen o producen la anulación, el aniquilamiento, la destrucción del don». ${ }^{13}$ Consideraremos esa estructura, mediante la cual lo imposible es condición de posibilidad y condición de posibilidad a la vez, como un cuasi-trascendental. Excederá por ello al acontecimiento del don -en su sentido restringido- para ampliarse a la experiencia en general. Si bien la noción de experiencia puede resultar problemática en la medida en que se la identifique a la presencia pura, ${ }^{14}$ la utilizaremos para dar cuenta de lo cuasi-trascendental en tanto relación con cierta exterioridad. Al reformular pues lo trascendental como cuasi-trascendental, y traduciendo eso como un pasaje de condiciones de posibilidad a condiciones de (im)posibilidad, la experiencia perderá pues ese carácter que la ligaba necesariamente a la presencia para ligarla, de allí en más -y aunque con una ligadura paradójica-, a lo imposible o lo incondicional. Si lo imposible es condición de (im)posibilidad de la experiencia, lo es en el doble sentido que indican los paréntesis del caso.

que lo hace bajo una perspectiva netamente atea, como es el caso de Martin Hägglund ( $c f$. Martin Hägglund, Radical Atheism. Derrida and the Time of Life. Stanford: Stanford University Press, 2008) o Patrick O' Connor (cf.Patrick O' Connor, Derrida: Profanations. New York: Continuum, 2010). Nosotros seguiremos la segunda línea, acordando con Hägglund en su crítica a Caputo. Según la lectura de Hägglund, al interpretar que aquello que para una perspectiva humana es imposible no lo es sin embargo para Dios, Caputo transforma a lo imposible en un ideal regulativo. Por su parte, la tesis que recorre el libro citado de O'Connor puede sintetizarse, según se explicita en las primeras páginas del texto, de la siguiente manera: no hay en el pensamiento derrideano espacio alguno para lo puro o lo sagrado, por lo tanto, Derrida de ninguna manera puede ser considerado como un pensador religioso (P. O' Connor, op. cit., p. 2). Es así que O'Connor reconoce seguir e intentar profundizar la línea de reflexión abierta por Hägglund (P. O'Connor, op. cit., p. 5).

13 J. Derrida, Dar (el) tiempo. 1. La moneda falsa, op. cit., p. 21.

14 Dicha aclaración es constante por parte de Derrida al momento de recurrir al término «experiencia». En «Firma, acontecimiento, contexto», por ejemplo, al referirse al concepto ampliado o cuasi-trascendental de escritura dice: «yo extendería esta ley [de la marca] a toda "experiencia" en general si aceptamos que no hay experiencia de presencia pura, sino sólo cadenas de marcas diferenciales». (J. Derrida, Márgenes de la filosofía, tr. Patricio Peñalver, Barcelona: Anthropos, 1989, p. 359.) 
(a) Condición de posibilidad. Lo imposible (lo anecomómico, el don) es condición de posibilidad de lo posible (la economía, lo dado), en la medida en que funciona como apertura.

Porque, a fin de cuentas, el desbordamiento del círculo mediante el don -si lo hayno conduce a una mera exterioridad inefable, trascendente y sin relación. Dicha exterioridad es la que pone en marcha el círculo, ella es la que da movimiento a la economía. Es ella la que (compro)mete en el círculo y la que le hace dar vueltas. Si es preciso rendir cuentas (a la ciencia, a la razón, a la filosofía, a la economía del sentido) de los efectos de círculo en los que se anula un don, dicho rendir-cuentas requiere que se tenga en cuenta lo que, no perteneciendo simplemente al círculo, (compro)mete en él y lo pone en movimiento. ${ }^{15}$

En este punto puede verse, mediante la figura del don como exceso, qué tipo de extrañeza mantiene lo imposible con lo posible. Pero cabe preguntarse, ¿por qué si se trata de aquello que «pone en marcha», «compro(mete)»y «pone en movimiento» al círculo de lo económico, se habla de lo imposible, acudiendo a un término de connotación negativa? Porque, justamente, aquello que pone en marcha el círculo es su exterioridad irreductible, es decir, su imposibilidad de economización o apropiación. Así, el don viene a determinar aquella apertura de lo imposible que no habría que comprender como un mero vacío. Lo imposible (se) da. Y aquello que (se) da, tal como reza el título del texto, es el tiempo. ${ }^{16}$ Volvamos entonces a la caracterización que hacía Mauss del don, en su diferencia con el intercambio comercial, como «plazo». Lo más interesante del planteo de Mauss, para Derrida, es que «la exigencia de la restitución "dentro de un plazo", con un "vencimiento" retardado, la exigencia de la différance circulatoria está inscrita, para aquellos que participan de la experiencia del don

15 J. Derrida, Dar (el) tiempo. 1. La moneda falsa, op. cit., pp. 38-39.

16 Jean-Luc Nancy afirma, en ese sentido: «C'est le temps qui est devenu en quelque sorte le donnée primordiale» (J-L. Nancy, «Derrida da capo», Rue Descartes, 52 (2006), p. 115). M. Hägglund expresa a su vez, en un párrafo de una notable claridad: «The deepest reason why there cannot be a closed circle is the constitution of time. The interval of time divides everything in advance and makes it impossible for anything to be closed in itself. Without the interval of time there would be neither gift nor economy, since there would be nothing separating the moment of giving from the moment of receiving. Consequently, the interval of time is the condition for anything to be given. Time is unconditionally given, since nothing can be given without being temporal. The given time is what makes economy possible, since it immediately separates the gift from itself and gives it over to calculation. But the given time is also what makes it impossible for economy to be a closed system, since the temporality of the gift cannot be mastered by calculation». (M. Hägglund, op. cit., pp. 37-38) 
y del contra-don, en la cosa misma que se da o que se intercambia». ${ }^{17}$ Es decir, antes que un gesto intencional del orden del contrato entre sujetos individuales o colectivos, «el movimiento del don/contra-don es una fuerza (una "virtud de la cosa dada", dice Mauss)». ${ }^{18}$ Por lo tanto, en la medida en que el tiempo, determinado como plazo, está dado en y por la cosa misma, Derrida se desplaza de la cosa al tiempo:

Se puede traducir de la siguiente manera: el don no es un don, no da sino en la medida en que $d a$ (el) tiempo. La diferencia entre un don y cualquier otra operación de intercambio puro y simple es que el don da (el) tiempo. Allí donde hay don, hay tiempo. [...] Ello, la cosa, requiere tiempo, pero requiere un tiempo delimitado, ni un instante ni un tiempo infinito, sino un tiempo determinado por un plazo, dicho de otro modo, un ritmo, una cadencia. La cosa no es en el tiempo, ella es o tiene (el) tiempo o, mejor aún, requiere tener, dar o tomarse (el) tiempo -y el tiempo como ritmo, un ritmo que no le adviene a un tiempo homogéneo sino que lo estructura originariamente. ${ }^{19}$

El tiempo entonces no sería una estructura homogénea sobre la cual se imprimirían las cosas al modo de una condición formal, separable o independiente de las cosas. De allí la bella imagen del tiempo como ritmo, en la medida en que lo rítmico marca cierta materialización del tiempo. Materialidad que en Derrida se piensa como exterioridad (en la línea de la concreción de la huella): «es -tal como se lo consigna en "La différance"- lo que podemos llamar espaciamiento, devenir-espacio del tiempo o devenir-tiempo del espacio (temporalización)». ${ }^{20}$ Lo imposible entonces, en tanto apertura, da la espacio-temporalidad, es decir, el espaciamiento, que es condición de posibilidad de la experiencia en la medida en que opera como síntesis. Así, Derrida dice:

Lo que pasa es que el syn-, la síntesis, el sistema o la sintaxis que articulan el don con el intercambio, es la différance temporal o, para mayor precisión, temporizadora, el término del plazo o el plazo del término que disloca todo «al mismo tiempo». La identidad entre don e intercambio no sería inmediata ni analítica. Tendría, en cierto modo, la forma de una síntesis a priori: síntesis porque requiere la temporización; síntesis a priori -a saber, necesaria- porque es requerida de

17 J. Derrida, Dar (el) tiempo. 1. La moneda falsa, op. cit., p. 46.

18 Ibid.

19 Ibid, p. 47

20 J. Derrida, Márgenes de la filosofía, tr. Carmen Gonzalez Marín, Madrid: Cátedra, 2003 , p. 48. 
entrada por la cosa misma, es decir, por el objeto mismo del don, por la fuerza o la virtud que sería inherente a él. ${ }^{21}$

(b) Condición de imposibilidad. En el mismo movimiento por el que abre y pone en marcha la circulación, lo imposible impide que tal circulación llegue a término, obturando la identificación a la que da lugar. Pero la identificación impedida es doble: impide la diferenciación identificante entre lo condicionante (lo imposible, lo aneconómico) y lo condicionado (lo posible, lo económico) en la medida en que impide la identificación de un imposible mismo. Remitámonos al ya mencionado potlatch, al exceso del exceso. Habíamos dicho que para Mauss el potlatch no era más que un caso dentro del sistema de los dones intercambiados. Sin embargo, en el párrafo que citábamos más arriba, dejábamos afuera una línea en la que Mauss decía que allí se trataba de «ver quién va a ser el más rico y también el más locamente gastador». ${ }^{22}$ Subrayando aquella expresión, Derrida marcaba que la locura que implica el potlatch amenaza con desarticular todo el sistema de los dones intercambios. Si el potlatch, en su límite, es una destrucción que no (res)guarda nada, difícilmente se lo pueda comprender como un caso de don.

Pero al margen del potlatch, que sigue representando para nosotros un caso culturalmente extraño, recurramos a otras figuras, las de la luz y el sol, que poseen la feliz característica de ser más abstractas y a su vez más «intuitivas». En algunas páginas de Glas, ellas aparecen ligadas esencialmente a la lógica del don que venimos intentando desplegar. Allí se afirma que «el proceso del don (antes del intercambio)», «no es un proceso sino un holocausto». ${ }^{23} \mathrm{El}$ don puro, se dice, como don de la luz, no puede diferenciarse del incendio. Reconstruyamos mínimamente el contexto de estas afirmaciones. Derrida, en lo que es su lectura más profunda y extensa de Hegel, se detiene en lo que sería la primera aparición del Espíritu, reconociéndola en lo que vendría a ser el primer momento de la religión natural, en la Fenomenología del espíritu, o el tercero en las Lecciones sobre la filosofía de la religión. Allí, el espíritu no se anuncia más que en su concepto, en la indeterminación abstracta; aun no se ha desplegado ni manifestado. Aparece entonces en tal momento pero como «pura luz, simple determinabilidad, medio puro, transparencia etérea de la manifestación donde nada aparece más que el aparecer, la luz pura del sol». ${ }^{24}$ Ahora bien, y esto es lo que nos interesa en este punto, entre la pura luz y el incendio no hay diferenciación posible. «Juego y pura diferencia, he ahí el secreto de un quema-

21 J. Derrida, Dar (el) tiempo. 1. La moneda falsa, op. cit., p. 46.

22 Ibid., p. 52.

23 J. Derrida, Glas. Paris: Galilée, 1974, p. 270 A.

24 Ibid., p. 265 A. 
todo [brûle-tout $]$ imperceptible, el torrente de fuego que se abrasa a sí mismo». ${ }^{25}$ De allí, pues, la imposibilidad de identificar una pura apertura: «Inversión pánica, sin límite: la palabra holocausto que se encuentra traducida como Opfer es más apropiada al texto que la palabra del mismo Hegel. En aquel sacrificio, todo (holos) es incendiado (caustos) y el fuego no podrá extinguirse más que atizado». ${ }^{26}$ «El don -continúa-, la donación del don, el regalo puro no se dejan pues pensar por la dialéctica a la que sin embargo dan lugar». ${ }^{27} \mathrm{La}$ pura apertura, pues, no se diferencia del abismo. Sobre ella, ninguna experiencia puede tener lugar. Así, nos vemos conducidos a plantear también la formulación inversa de la que acabamos de analizar, reconociendo la necesidad del doble vínculo que planteábamos. Es decir, también lo posible es condición de (im)posibilidad de la experiencia. Repitamos pues el esquema anterior para explicarlo.

(a) Condición de posibilidad.Pero la oscilación entre apertura y abismo no es, a decir verdad, más que un efecto económico. Es decir, la distinción entre la apertura por un lado, y la destrucción por otro, responde a cierto proceso de estabilización e identificación que depende de la esfera de lo posible, en la medida en que una pura apertura y una pura destrucción no serían en sí mismas distinguibles. En De la gramatología Derrida es muy claro al respecto. Allí dice, con respecto a la pureza: «mito de origen de un mundo deshabitado, de un mundo ajeno a la huella: presencia pura del presente puro, que se puede llamar indiferentemente pureza de la vida o pureza de la muerte». ${ }^{28}$ En ese contexto, la potencia del concepto de huella venía dada justamente en cuanto esta funcionaba como una inscripción repetible que sin embargo mantenía al presente de su inscripción como imposible. A su función económica se refería Derrida cuando decía: «Sin una retención en la unidad mínima de la experiencia temporal, sin una huella que retuviera al otro como otro en lo mismo, ninguna diferencia haría su obra y ningún sentido aparecería». ${ }^{29}$

(b) Condición de imposibilidad. Este punto fue el más largamente desarrollado más arriba en lo concerniente a la aporía del don: la circulación económica que, según acabamos de ver, lo condiciona para resguardarlo de su propia destrucción es aquello mismo que impide que el don aparezca o este presente en cuanto tal.

25 Ibid., p. 266 A.

26 Ibid., p. 271 A.

27 Ibid.

28 J. Derrida, De la gramatología, tr. Oscar Del Barco, México: Siglo XXI, 2005, p. 366.

29 Ibid, p. 81. 


\section{Cuasi-Trascendentales II: LA (IM)POSIBILIDAD DEL Sistema}

Queda todavía por comentar aquella inquietud que guardaba Derrida con respecto a la posibilidad de un «un ser conjuntamente, el ser-al mismo tiempo, la síntesis, la simetría, la sintaxis o el sistema, el syn que articula dos procesos jurídicamente tan incompatibles como el del don y el del intercambio». ${ }^{30} \mathrm{La}$ estrategia derrideana es la siguiente: si se pone en cuestión la referencia (del) como tal, la circulación no tiene un campo restringido, y no habría por tanto cambio de planos al pasar de la economía en cuanto circulación de bienes materiales a la circulación de los significantes o las marcas en el discurso. Así, Derrida encuentra que en el discurso de Mauss se evidencian las dificultades que conlleva el intento de unificar bajo un sistema al don como exceso en la circulación por un lado, y al intercambio como su cumplimiento por otro. La objeción derrideana se detiene justamente en los procesos de nominación que allí tienen lugar. Para Derrida, «aquello que el lingüista o el gramático cree reconocer como un nombre» es la «unidad de un sentido». ${ }^{31}$ Un nombre sería así el término económico por excelencia, el término del saber. La intervención derrideana se deja pues adivinar: nombrar el don sería inscribir en la economía aquello que la interrumpe, su punto de fuga o de exceso: «Si el don se anula en la odisea económica del círculo en cuanto aparece como don o en cuanto se significa como tal don, ya no hay más "lógica del don". Y se puede apostar que un discurso consecuente sobre el don se torna imposible: no atina a dar con su objeto y habla siempre, en el fondo, de otra cosa». ${ }^{32}$ Lo que Derrida se pregunta entonces es si la subsunción del potlatch y del intercambio como casos de don no enloquece al núcleo semántico del término don. Es decir, en un estrato del uso del discurso, ¿no pierde el don su significado si se lo identifica a la destrucción o al intercambio comercial?

Ahora bien, tal imposibilidad no le está reservada al discurso de Mauss en particular, sino que se extiende al procedimiento del nombrar en general. Así, vemos cómo la problemática que Derrida reconocía en el Ensayo sobre el don -texto «comentado» o discurso objeto-, (se) contagia a Dar (el) tiempo -texto «comentador» 0 «meta-discurso»-. Entre Mauss y Derrida no habría entonces más que un cambio de signo ante dicha imposibilidad: de la resistencia a su productividad. Detengámonos pues en la palabra dar: no sólo en el Ensayo o en Dar (el) tiempo, sino a su vez en la circulación que se tiende entre este último en su edición francesa y en su versión española. En su texto Derrida se pregunta si se trata del mismo régimen semántico en las locuciones del dar en las que lo dado es alguna cosa u objeto material, y aquellas en las que lo que se da no

30 J. Derrida, Dar (el) tiempo. 1. La moneda falsa, op. cit., p. 44.

31 Ibid., p. 20.

32 Ibid., p. 32. 
es un objeto sino un símbolo, una persona o un discurso. Es decir, ¿acaso el complemento de «objeto» del acto de «dar» no altera radicalmente el sentido del acto de dar? Así:

¿Qué tienen en común dar una sortija, una pulsera, dar de beber y de comer, por una parte; y dar una impresión, una emoción, dar un espectáculo o una representación, otras tantas expresiones que apelan irreductiblemente al idioma y que son, en principio, de limitada traducibilidad? ¿Qué tienen en común y cuál es el paso entre «dar la hora» $\mathrm{y}$ «dar un premio» (en el sentido de la subasta: «le doy tanto por esto»), entre «dar facilidades» $\mathrm{y}$ «dar una orden», entre «dar una información», «dar un curso, una asignatura y un seminario», «dar una lección», que es algo muy distinto, $\mathrm{y}$ «dar el pego», «dar signos», etc.? ${ }^{33}$

Pero además de aquellos múltiples sentidos del verbo dar, Derrida señala la ruptura idiomática que se da en francés «entre la sintaxis del dar (el verbo) y la sintaxis del don (nombre)», preguntándose si «i[e]s válida la consecuencia idiomática que va de lo que significa "dar" a lo que significa "don"?». ${ }^{34}$ Ruptura que, vale mencionar, es aun mayor en nuestro español actual. De hecho, el nombre asociado al verbo «dar» es el de lo «dado», mientras que al nombre «don» corresponde el verbo «donar». Así, en español se pierde la potencia sistematizadora que se pone en juego en el texto de Derrida. En español, sobre todo el don pero a su vez lo dado, en tanto nombres, se asocian a atributos que, las más de las veces, comportan el misterio de una destinación, en francés, en cambio, une donné reviste, entre sus sentidos, un valor de neutralidad máxima, que se traduce como dato.

Ahora, si el don efectivamente pudiera funcionar como «equivalente general que permita la traducción, la metaforización, la metonimización, el intercambio, en el interior de un círculo semántico finalmente homogéneo», entonces estaríamos ante un significado o significante trascendental. Continúa Derrida:

Al desempeñar el papel de un algo dado trascendental, aquél orientaría la multiplicidad y suministraría la categoría trascendental, categoría de la cual todas las demás categorías de dado (ser/haber, cosa/persona, sensible natural/simbólico, etc.) serían determinaciones particulares, sustitutos metafórico-metonímicos. Sabemos que la palabra «trascendental» califica, en primer lugar, la categoría que excede todo género (transcendit omne genus) y hace así posible cualquier otra determinación categorial. ${ }^{35}$

33 Ibid., p. 55.

34 Ibid., p. 59.

35 Ibid., p. 58 
Si, tal como dice Derrida, «la estructura de este don imposible es también la del ser -que se da al pensamiento a condición de no ser nada (ningún entepresente) - y la del tiempo», ${ }^{36}$ y si a su vez no «puede entonces pensarse más la donación a partir del ser, sino "lo contrario"», ${ }^{37}$ cabe preguntarse, jes entonces la estructura del don un trascendental? Si así fuera, debería haber

una línea que separe dos grandes estructuras del don, estructuras, al menos, de índole tal que se las localice en el idioma. Habría, por una parte, el don que da alguna cosa determinada (algo dado, un presente de cualquier tipo, cosa personal o im-personal, cosa «natural» o símbolo, cosa o signo, signo no discursivo o discursivo, etc.); y, por otra parte, el don que da no ya lo dado sino la condición de algo dado presente en general, un don que da, por consiguiente, el elemento de lo dado en general. Así es como, por ejemplo, «dar (el) tiempo» no es dar un presente dado sino la condición de presencia de todo presente en general; «dar a luz» [en francés: «donner le jour»] no da nada (ni siquiera la vida que se supone que da, digamos por comodidad, «metafóricamente») sino la condición de todo lo dado en general. Dar (el) tiempo, dar a luz, el día o la vida, es no dar nada, nada determinado, pese a que es dar el dar de todo posible dar, pese a que es dar la condición de dar. ${ }^{38}$

Derrida pregunta pues: «¿Qué es lo que distingue al principio a esta partición de la partición trascendental a la que se parece?» A lo que responde, y aquí se evidencia aquella relación irreductible entre lo que señalábamos como condiciones de (im)posibilidad de la experiencia y condiciones de (im)posibilidad del sistema o la sistematización: «En ella se percibe no ya una línea tajante que separa lo trascendental de lo que está condicionado, lo condicionante de lo condicionado, sino el repliegue de indecidibilidad que permite invertir todos los valores: el don de la vida viene a ser el don de la muerte, el don del día el don de la noche, el don de la luz el don de la oscuridad, etc.». ${ }^{39}$ Así, tomando las multiplicidades semánticas que venimos de reconocer al término «don», el repliegue de indecidibilidad formularía la siguiente pregunta: jla posibilidad de pensar algo así como el don -su significado- no vendría dado, en prime lugar, por todos los múltiples casos de don, justamente en las marcadas diferencias entre, por sólo nombrar algunos de ellos, «dar una pulsera», «dar de comer», «dar facilidades»?

36 Ibid., p. 35.

37 J. Derrida, Glas, op. cit., p. 269 A.

38 J. Derrida, Dar (el) tiempo. 1. La moneda falsa, op. cit., p. 59.

39 Ibid., p. 60. 
Quizá uno de los textos en los que con más claridad se tematice este repliegue no siempre explicitado sea, no casualmente, Aporías. ${ }^{40}$ Allí, en un texto que apunta a Heidegger y que, tal como lo indica su título, termina en un callejón sin salida, Derrida trata la temática de la muerte abordándola desde dos perspectivas. Por un lado, con un abordaje histórico-antropológico, utilizando entre otros el texto de Philippe Ariès, Historia de la muerte en Occidente, y por otro, desde la analítica existencial de Ser y tiempo. Según la argumentación de Heidegger, tal como la comprende Derrida:

Los saberes antropológicos -suele decirse- tratan de la muerte según la cultura y la historia; se supone que los saberes biogenéticos tratan de la muerte según la naturaleza. Sin embargo, por necesarios y ricos que puedan ser, semejantes saberes deben presuponer, dice en resumidas cuentas Heidegger, un concepto de la muerte propiamente dicha. Éste sólo se lo proporciona la analítica existencial. Heidegger describe dicha relación de dependencia recurriendo a la idea clásica de un orden, orden de prelación, de precedencia y de presuposición (vorliegen, vorausestzen), orden asimismo de fundación: están los cimientos fundadores del fundamento y la estructura fundada que los presupone. ${ }^{41}$

Ante esa distinción trascendental, que pretende marcar la prioridad de uno de los dos abordajes, Derrida repite la indecidibilidad que habíamos señalado más arriba. Veamos el cierre del texto que, tal como decíamos, es paradigmáticamente aporético:

Por una parte, se puede leer semejante historia de la muerte en el Occidente cristiano, por ejemplo la de Ariès, y cualesquiera que sean su riqueza o su novedad, como una pequeña monografía que viene a ilustrar en nota hasta qué punto ésta depende, en sus presupuestos, de la potente y universal delimitación que es la analítica existencial de la muerte en Sein und Zeit. Ésta desborda y, por consiguiente, incluye de antemano ampliamente el trabajo del historiador, por no decir del biólogo y del teólogo de la muerte. Y asimismo lo condiciona y está constantemente presupuesta en él.

Pero, por otra parte, se puede tener la tentación, por el contrario pero igual de legítimamente, de leer Sein und Zeit como un pequeño documento tardío entre tantos y tantos otros en el gran archivo en el que se acumula la memoria de la muerte en la Europa cristiana. Cada uno de estos dos discursos sobre la muerte es mucho más comprensivo que el otro, más grande y más pequeño que lo que

40 J. Derrida, Aporías. Morir-esperarse (en) los «límites de la verdad», tr. Cristina de Peretti, Barcelona: Paidós, 1998.

41 Ibid., p. 78. 
trata de incluir o de excluir, más o menos originario, más o menos antiguo, joven o viejo. ${ }^{42}$

No se trata pues de una aporía en el saber. ${ }^{43}$ No es la detención de una puesta entre paréntesis que suspendería el juicio. Si Derrida designa sus términos operatorios como cuasi-conceptos o como «concepto[s] exacerbado[s], agujereado[s]», ${ }^{44}$ es justamente porque aquello que los agujerea es un no-saber, un fuera del concepto que no puede entenderse como su no-saber o $s u$ afuera. Venimos de mostrar esa oscilación a propósito del texto de Heidegger, y será justamente en una explicación con éste que Derrida enfocará el no-saber propio de su obra. En «Sobre el don. Una discusión entre Jacques Derrida y Jean-Luc Marion», Derrida responde, alrededor del tema de la revelación, confesando aquel no-saber no relevable que se mantiene al momento de distinguir la condición de lo condicionado:

Lo que realmente no sé, y confieso que no lo sé, es si lo que estoy analizando o tratando de pensar es anterior a mi propia cultura, a nuestra propia cultura, es decir, a la herencia judeo-cristiana y griega del don. Cuando me intereso por la khora, intento alcanzar una estructura que no es la khora como la interpretó Platón, sino una propia en contra de la de Platón. No sé si esta estructura es realmente anterior a la que aparecerá luego bajo el nombre de religión revelada o incluso de filosofía, o si es por medio de la filosofía o de las religiones reveladas, las religiones del libro, o de cualquier otra experiencia de revelación como podemos pensarla retrospectivamente. Debo confesar que no puedo escoger entre estas dos hipótesis. Traducido al discurso de Heidegger, que apunta a la misma dificultad, esta es la distinción entre Offenbarung y Offenbarkeit, la revelación y la revelabilidad. Heidegger decía, y esta es su posición, que no habría revelación u Offenbarung sin la estructura previa de la Offenbarkeit, sin la posibilidad de la revelación y la posibilidad de la manifestación. Esa es la posición de Heidegger. No estoy muy convencido de esto. Tal vez es por medio de la Offenbarung que la Offenbarkeit resulta históricamente pensable. En realidad, esta es la razón por

42 Ibid., p. 129.

43 John Protevi considera que, a partir de fines de los años 80, la noción de aporía se transforma en el hilo conductor privilegiado en el texto derrideano ( $c f$. P. Patton y J. Protevi (eds.), Between Derrida and Deleuze. London: Athlone Press, 2002, p. 184.) Richard Beardsworth también considera a la aporía como un concepto central; de hecho, en su Derrida \& the Political, es sobre ese concepto que se lee la irreductible politicidad de la obra derrideana. $C f$. R. Beardsworth, Derrida \& the Political. New York: Routledge, 1996.

44 J. Derrida, El tiempo de una tesis: Deconstrucción e implicaciones conceptuales, $\mathrm{tr}$. Cristina de Peretti, Barcelona: Proyecto A Ediciones, 1997, p. 39. 
la que constantemente tengo dudas. Esto hace parte de - ¿cómo denominarlo?digamos, mi encrucijada. ${ }^{45}$

Ahora, si bien ello no redunda en una renuncia del saber (en «una especie de abdicación adoradora y fiel» ${ }^{46}$ ), sí marca que la imposibilidad de su clausura económica es la condición de posibilidad del pensar. Así, pensar es pensar lo imposible. De allí que «lo imposible [sea] la especialidad de la deconstrucción».47 Aunque, si el verbo ser lo inscribe todavía en una lógica proposicional, habría mejor que decir: se piensa lo imposible. Con respecto al don como nombre de lo imposible Derrida se pregunta:

¿Por qué y cómo puedo pensar que el don es lo imposible? ¿Y por qué se trata precisamente aquí de pensar, como si el pensamiento, la palabra pensamiento, no se ajustase sino a esa desproporción de lo imposible, no anunciándose siquiera, como pensamiento irreductible a la intuición, irreductible también a la percepción, al juicio, a la experiencia, a la ciencia, a la fe, más que a partir de esta imagen de lo imposible? ¿a partir de lo imposible en la forma del don? ${ }^{48}$

Pero, tal como vimos, la desproporción o la irreductibilidad de lo imposible no implican la mera negatividad de una no-relación. Por lo tanto, tampoco habría pensamiento sin intuición, percepción o juicio, es decir, sin la reapropiación económica de lo posible. Habría que decir entonces que se piensa entre lo posible y lo imposible; se piensa lo (im)posible. Esto es, cierto devenir posible de lo imposible tanto como un devenir imposible de lo posible. El pensamiento sería entonces ese círculo quebrado que pasa entre lo (im)posible. Una nueva epojé: no un círculo neutralizante, sino la apertura por lo alto y por lo bajo, de

45 J. Derrida, «Sobre el don. Una discusión entre Jacques Derrida y Jean-Luc Marion (Moderada por Richard Kearney)», Anuario colombiano de fenomenología, III (2009), pp. 265-266. En nota a Marx e hijos Derrida repite este planteo: «Esto se asemeja al posible debate a propósito de la Offenbarung (revelación) y Offenbarkeit (posibilidad de la revelación y de la manifestación). Heidegger parece hacer siempre de la posibilidad de revelación una estructura de la existencia más profunda, más antigua y, por lo tanto, independiente, sobre cuya base la revelación religiosa, tal o cual religión histórica, se vuelve posible de forma secundaria y se determina. Sin embargo, podemos estar tentados de oponer a este poderoso y clásico argumento al menos una pregunta: ¿y si, como tal, la revelación de la revelabilidad misma se manifestara únicamente a través del acontecimiento (histórico) de la revelación?, etcétera.» (J. Derrida, «Marx e hijos», en Michael Sprinker (ed.), Demarcaciones espectrales. En torno a Espectros de Marx, de Jacques Derrida, tr. Marta Malo de Molina, Alberto Riesco Sanz y Raúl Sanchez Cedillo, Madrid: Akal, 2002, p. 298.)

46 J. Derrida, Dar (el) tiempo. 1. La moneda falsa, op. cit., p. 39.

47 J. Derrida, Resistencias del psicoanálisis, tr. Jorge Piatigorsky, Buenos Aires: Paidós, 2005 , p. 74.

48 J. Derrida, Dar (el) tiempo. 1. La moneda falsa, op. cit., p. 20. 
una puesta entre paréntesis que, agujereando el espacio de lo propio, de cuenta de la interrupción que hay en la relación a-sí o con-sigo de todo fundamento apodíctico.

Diego Abadi se licenció recientemente en la Facultad de Filosofía y Letras de la Universidad de Buenos Aires, defendiendo una tesis de licenciatura titulada "Derrrida. Una lectura sistemática", dirigida por la Dra. Mónica B. Cragnolini.

Línea de investigación:

Filosofía francesa contemporánea, enfocándose actualmente en el estudio de la obra de Jacques Derrida y Gilles Deleuze.

Publicaciones recientes;

(2010) «El resto de la historia», en Inconsciente e historia después de Freud: cruces entre filosofía, psicoanálisis e historiografía, Omar Acha y Mauro Vallejo (comps.), ISBN: 978-987574-435-6, Editorial Prometeo, 2010, pp. 205-218.

(2011) «El concepto de humeano de institución en Empirismo y subjetividad de Gilles Deleuze», en Discusiones en torno a la naturaleza humana. Homenaje a David Hume, Romina Pulley y Nahuel Charri (comps.), ISBN: 978-987-544-409-6.

Dirección electrónica: diego.abadi@gmail.com 
